\title{
Longitudinal Trajectories of Post Traumatic Stress Disorder(PTSD) in Medical Staff After Outbreak of Coronavirus (COVID-19) in China
}

\section{Han Sheng}

Affiliated Hospital of Jiaxing University

Rong Wang ( $\sim$ a043119@163.com )

Department of Anesthesiology and Pain Medicine

Ming Yao

Department of Anesthesiology and Pain Medicine

\section{Qinghe Zhou}

Department of Anesthesiology and Pain Medicine

\section{Zhihong Zhu}

Affiliated Hospital of Jiaxing University

\section{Yeping Fei}

Affiliated Hospital of Jiaxing University

\section{Xuyan Zhou}

Affiliated Hospital of Jiaxing University

Qifei Liu

Department of Oncology, China

\section{Research article}

Keywords: PTSD, Trajectories, Mental health, Medical staff, COVID-19, Risk factors

Posted Date: August 23rd, 2021

DOI: https://doi.org/10.21203/rs.3.rs-829485/v1

License: (c) (1) This work is licensed under a Creative Commons Attribution 4.0 International License. Read Full License 


\section{Abstract}

Background: In the novel coronavirus disease (COVID-19) pandemic, medical staff is the main force for aiding in the control of the rapid spread. They have to risk lives to undertake the high-pressure task which may cause immediate and long-term psychological problems. This study aims to explore the trajectories of post-traumatic stress disorder (PTSD) over time after the outbreak and determine predictors associated with each trajectory.

Methods: 448 medical workers participated in the investigation and completed the Posttraumatic Stress Disorder Self-Rating Scale (PTSD-SS) for the first PTSD screening at 1 month after the outbreak and 259 (57.81\%) of them finished the second round at 12 months. According to whether the medical staff had close contact with the COVID-19 patient, participants were divided into close contact group (CC group) and non-close contact group (non-CC group). While in each group, subgroups were created based on the time-varying changes of developing PTSD. Distinct patterns of PTSD symptom trajectories were established according to the different development of PTSD in respective subgroup. Then, repeated-measure analysis of variance(ANOVA), bivariate and multivariate logistic regressions were used to examine predictors for trajectory membership.

Results: Four trajectories of PTSD symptoms were found both in CC and non-CC group, namely, resilience $(25.28 \%, 45.24 \%$, respectively), recovery $(36.26 \%, 32.74 \%$, respectively), chronic $(16.48 \%, 10.71 \%$, respectively), and delayed $(21.98 \%, 11.31 \%$, respectively). ANOVA revealed that PTSD scores were significantly changed through time both in CCs and non- CCs. With bivariate and multivariate analyses, several socio-demographic predictors and work experience related factors were found in the $\mathrm{CC}$ group, while limited ones in the non-CC group. This means that although the trajectory trends are similar between these two groups, the methods of psychological intervention may need to be treated differently. Furthermore, CC group had less resilient individuals $(p=0.002)$ and more delayed PTSD sufferers $(p=0.022)$ compared with non-CC medical staff, which suggest that CCs were more likely to experience PTSD course and encounter long-term psychological problems.

Conclusions: A considerable number of medical personnel have long-term PTSD, both in CC group and non-CC group, which deserve public attention. Identified factors may indicate preventive and treatment interventions for medical workers with PTSD symptoms.

\section{Background}

The world is currently facing the Coronavirus Disease (COVID-19) pandemic with a novel coronavirus, SARS-CoV-2, initially emerged in Wuhan, China in the end of 2019[1-3]. It quickly spread outside of China, and become the largest outbreak of atypical pneumonia since the severe acute respiratory syndrome (SARS) happened in 2003[4], leading the World Health Organization (WHO) Emergency Committee to declare that the outbreak constitutes a Public Health Emergency of International Concern (PHEIC) on January 30th 2020[3], and a pandemic on March 11,2020. The pandemic causes a considerable degree of public panic, because of the high transmission rate, high death toll, as well as the various symptoms among patients, and the capability of asymptomatic spread[5]. To retard the spread of the virus, some form of lockdown and travel restrictions were imposed in many countries [4]. The resulting public anxiety, social isolation and economic uncertainty have given rise to significant increases in mental health concerns, including stress, dread feeling, loneliness, depression, and suicidal ideation $[4,6]$.

Medical workers, as a member group of the public, are also victims of the COVID-19, but still have the responsibility to eliminate the epidemic. They have to fight on the front lines and as the essential group controlling large-scale disasters and epidemics. The primary transmission route of COVID-19 is aerosol and close contact, which put medical staff at high risk of exposure. WHO estimated that $30-50 \%$ of the affected population suffered from varying degrees of psychological distress, among which physicians and nurses were an important group $[7,8]$. Being a medical worker is regarded as one of the most consistent predictors for psychiatric morbidity [1, 9], and many of them often remain undetected. Investigation indicates that PTSD rate of medical staff in emergency care settings ranges from $10 \%$ to about $20 \%$, and particularly at risk for psychological distress because of the highly stressful work-related situations, which include [1]: management of critical medical situations, caring for severely traumatized people, frequent witnessing of death and trauma, operating in crowded settings, interrupted circadian rhythms due to shift work. And the current COVID-19 pandemic brings more pressure to increase the risk for PTSD, such as the unprecedented numbers of critically ill patients, usually with an unpredictable course of the disease, the lack of effective treatment or treatment guidelines [5]. Until now, with more than 194 million[10] people infected worldwide and the spread is far from being contained, the 
impact on medical staff's mental health may have lasting effects. Therefore, continue to investigate the psychological effect on medical staff has become increasingly important.

Posttraumatic stress disorder (PTSD) is a mental disorder that affects approximately $3 \%$ to $4 \%$ of the general population, and $32 \%$ of PTSD are emergency personnel and first responders [11]. PTSD can occur after a single traumatic event or from prolonged exposure to trauma(Bisson., et al., 2015), and an acute post-trauma period, defined as the 30 days post-trauma, may be important in distinguishing individuals with PTSD from normal people [12]. Moreover, short-term observations are limited in showing psychological effects, a growing literature focused on long term PTSD for more than 1 year suggest that there is considerable heterogeneity in how symptoms present over time following traumatic exposure. This point of view was validated in population of traumatic childbirth, motor vehicle crash / motorcycle crash, assault, burn, work accident $[12,13]$. Generally, these fluctuations may follow separate patterns and can be described as four latent trajectories: resilience (minimal/mild disruption or no elevated symptoms), recovery (initial significant disruption and elevated PTSD symptoms which can be solved after some time), chronic (elevated PTSD symptoms which are maintained over time) and delayed (worsening of symptoms over time). Although the etiology of PTSD after COVID-19 outbreak has been investigated, most of the studies were cross-sectional, and research regarding the progression of COVID-19 related PTSD is less represented. And there has been no research has systematically investigated the different trajectories that PTSD can follow after COVID-19 spread, including trajectory patterns and their underlying determinants.

Throughout history, mankind has been affected by various infectious disease epidemics. And it may happen again and poses a challenge to psychological resilience. We conducted the present study at 1 month and 12 months after the SARS-CoV-2 spread, using a more reliable and valid instrument, trying to focus on the long-term psychiatric crisis among medical staff after the Coronavirus outbreak, and to provide a scientific basis of psychological support for them when new epidemic occurs, further helping them get rid of the low work efficiency caused by psychological problems and maintain spiritual health. Furthermore, most research focuses on the medical staff who are close contact with COVID-19 patients, but the epidemic has a great impact on the whole medical system, so it is necessary to pay attention to the psychological development both in close contact(CC) and nonclose contact(non-CC) medical staff with COVID-19 patients. Thus, the present study would like to extend the observation time and observation population aims to

- explore the dynamic process of long-term PTSD and identify distinct trajectories of PTSD in medical staff after the Coronavirus outbreak.

- find out the association between PTSD trajectories and socio-demographic and work experience related variables.

- compare the characteristics of the PTSD trajectories in different groups between the close contact and the non-close contact with COVID-19.

\section{Methods}

\section{Design, procedure, and participants}

A prospective, longitudinal study was conducted to examine PTSD score from medical staff after the outbreak of coronavirus (COVID-19). According to literature review, symptom development 30 days after the traumatic event may be an important timing to distinguish people with acute PTSD [12], and PTSD symptoms tended to be most severe at 12 months, suggesting an 'anniversary reaction' in the time course of PTSD symptoms [2].Thus, the current study conducted an online investigation carried out 1 month and 12 month after outbreak (Jan 31 to Feb 2, 2020;Jan 31 to Feb 2, 2021), respectively. Chinese medical workers were invited to participate in the online survey though Wenjuanwang platform (https://www.wenjuan.com/). Considering the different exposure levels of COVID-19 patients may have different effect on psychology, and in order to avoid data interference leading to false positive results, participants were divided into CC group and non-CC group according to the item of scale (whether had close contact with COVID-19 patients), and then discussion was conducted about the respective group. In the end, 259 participants from 7 provinces and municipalities (Shanghai, Jiangxi, Zhejiang, Beijing, Jiangsu, Guangxi, Hainan ) were involved in the current study, including 91 in the CC group and 168 in the non-CC group. (study flow diagram in Fig. 1). A written consent in the first section of 
online survey was given to all participants before filling the questionnaire. This study has been approved by the Institutional Review Board of the First Hospital of Jiaxing.

Sample size: according to Gorsuch method [14], the sample size was 5-10 times the number of independent variables. Based on the self-rating scale of post-traumatic stress disorder(PTSD-SS), it contained 24 independent variables. IF 10 samples were taken for each independent variable, and adding $10 \%$ for non-response rate, the final sample size estimation formula is: $\mathrm{N}=(24 * 10) \star \nabla 1+$ $10 \% \nabla=264$. Combined with the actual situation that it's a longitudinal study with a long time span in the form of online survey, we try our best to expand the sample size on this basis. In total, 448 participants completed this investigation at 1 month and $259(57.81 \%)$ of them completed the second wave (at 12-months) of the PTSD screening. The participants $(n=259)$ ranged in age from 19 to $55(M=33.81, S D=7.54)$ at 1 month.

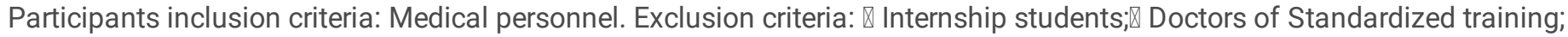
\Medical staff with sick leave or maternity leave more than 2 weeks during the epidemic period; $\nabla$ Have clear diagnosis of anxiety

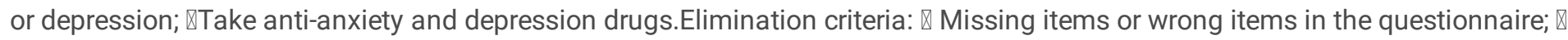
Lost to follow up.

\section{Measurements}

PTSD Scale. The original Posttraumatic Stress Disorder Self-Rating Scale (PTSD-SS) is a Chinese version scale developed according to the diagnostic criteria of PTSD set by the Diagnostic and Statistical Manual of Mental Diseases, fourth edition (DSMIV) and the Chinese Classification of Mental Disorders. The scale was introduced into China and modified in 1998 and is now widely used to measure PTSD of traumatic events $[2,15]$. It is a 24-item self-report rating measure which assesses severity of PTSD symptoms in which participants are asked to rate how much they were bothered by their symptoms on a Likert scale $(0=$ not at all, 5 =extremely). Scores on the PTSD scale range from 0 to 120, and a score of greater than 50 has been recommended as a cutoff for a probable diagnosis of PTSD in traumatic survivors(Lei et al., 2012). The higher the score, the more serious it is. If the total score $\geq 60$ would be evaluated as severe PTSD. It contains 5 subscales[15]: trauma ( 1 items), re-experience symptom(7 items), avoidance behaviors (7 items), emotional numbing and hyperarousal ( 7 items), Social dysfunction symptom (2 items). The PTSD scale has satisfactory internal reliability (Cronbach- $a=.9207)$.

Questionnaire. The following variables were included general socio-demographic characteristics: age (years, $\pm s$ ), gender, profession (nurses/doctor), years at hospital, marital status (married/unmarried), technical title (junior, intermediate, senior), educational level (junior college , bachelor degree, master and higher), have a child/children (yes/no); work experience related information: emergency rescue experience in major public health events (yes/no), working in high epidemic areas(yes/no), contact with COVID19 patients (yes/no). The criteria for identifying high-risk areas comes from Protocol on Prevention and Control of Novel Coronavirus Pneumonia (Edition 5) released by the National Health Commission. The medical staff who contacted with patients diagnosed with COVID-19 in mild, common and severe were identified as close contacts, while those who contacted with suspected patients and non- COVID-19 patients were identified as non-close contacts. The COVID-19 diagnostic standard is based on the Diagnosis and Treatment Protocol for Covid-19 (Trial Version 7) issued by the NHC.

\section{Statistical analyses}

All statistical analyses were performed using SPSS statistics (version 23). If the assumption of normality was violated, nonparametric tests were considered. The data of CC group and non-CC group were collected separately, and the following procedures were carried out respectively. Changes in PTSD symptoms from 1 month to 12 months after COVID-19 spread were examined with a repeated-measure analysis of variance (ANOVA). Group differences associated with selected socio-demographic and work experience related variables were examined using one-way ANOVA for continuous measures and Chi-square for categorical variables. Fisher's exact test was used in the case of a low frequency of the relevant variable. One-way Welch ANOVA was reported when the assumption of homogeneity of variance was violated. Logistic regression analysis was applied to determine main and secondary factors that differentiated PTSD trajectories. Variables significantly associated with trajectory membership in the univariate analysis were subjected to multivariate logistic regression procedure with the entry method. The resilient group served as the reference category and $\beta$ values and odds ratios (OR) with $95 \%$ Cls were reported. All assumptions including multi-collinearity were met. Finally, a "non-resilient" group (recovery + chronic + delayed) was formed by combining groups of medical staff with PTSD at any time after COVID-19 outbreak and then compared to the resilient group to determine the factors associated with 
development of COVID-19 related PTSD. Variables of the questionnaire were then included into binary logistic regression. $P$-values $<.05$ were considered statistically significant and all tests were two-sided. At last, using Chi-square to analyze the differences of trajectories between CC group and non-CC group.

\section{Results}

1. COVID 19-related PTSD score trajectories at 1 month and 12 months after outbreak of coronavirus

Figure 2 shows mean PTSD symptom scores in different groups. A repeated-measure analysis of variance (ANOVA) was used in CC group and non-CC group respectively. CC group: $\mathrm{F}$ group $(3,12)=63.470, p<.001$, partial $\eta^{2}=.94$, $\mathrm{F}$ time $\times$ group $(3,12)=$ $70.125, p<.001$, partial $\eta^{2}=.95$. non-CC group: $\mathrm{F}$ group $(3,15)=50.675, p<.001$, partial $\eta^{2}=.91, \mathrm{~F}$ time $\times$ group $(3,15)=40.641, p$ $<.001$, partial $\eta^{2}=.89$. It revealed that PTSD scores of the resilient, recovery and chronic groups were statistically significantly decreased from 1 month to 12 months after outbreak of COVID-19 both in CC group and the non-CC group, whereas PTSD scores of the delayed group reported a significant increase in both two groups.

\section{Differences between trajectories}

The descriptive statistics for selected socio-demographic and work experience related variables are summarized in Table 1 and Table 2. In CC group, it reveals that unmarried, junior female nurses have a significantly high probability of being resilient individuals, while the person who has emergency rescue experience in major public health events are more tend to be in the recovery group. Medical staff with rich rescue experience know better about the threat of epidemic which make them get more psychological troubles, meanwhile, they also have the ability to handle these situation which allows them to recover quickly. The person who has a child / children or has the experience of working in high epidemic areas of Covid-19 were more likely to suffer from chronic or delayed PTSD. In non-CC group, only the technical title of medical staff and the experience of emergency rescue in major public health events were found to be significant between trajectories. 
Table 1

Socio-demographic, work experience related characteristics among four PTSD trajectories in CC group

\begin{tabular}{|c|c|c|c|c|c|}
\hline \multirow[t]{3}{*}{ Variables } & Resilient & Recovery & Chronic & Delayed & F or $X^{2}$ \\
\hline & $(n=23)$ & $(n=33)$ & $(n=15)$ & $(n=20)$ & \\
\hline & $\begin{array}{l}M(S D) \text { or } n \\
(\%)^{a}\end{array}$ & $\begin{array}{l}M(S D) \text { or } n \\
(\%)^{a}\end{array}$ & $\begin{array}{l}M(S D) \text { or } n \\
(\%)^{a}\end{array}$ & $\begin{array}{l}M(S D) \text { or } n \\
(\%)^{a}\end{array}$ & \\
\hline $\mathrm{Age}^{\mathrm{b}}$ & $31.39(6.37)$ & $34.33(5.86)$ & $34.73(6.96)$ & $36.95(7.11)$ & 2.695 \\
\hline Gender(Female $)^{c d}$ & $22(95.7)$ & $28(84.8)$ & $12(80.0)$ & $12(60.0)$ & -* \\
\hline Profession $^{c d}$ & $22(95.7)$ & $29(87.9)$ & $13(86.7)$ & $16(80.0)$ & - \\
\hline \multicolumn{6}{|l|}{ Nurses/doctor(Nurses) } \\
\hline Years at hospital $^{\text {b }}$ & 10.39(7.53) & $12.18(6.54)$ & $12.80(5.77)$ & $15.20(8.15)$ & 1.687 \\
\hline marital status ${ }^{c}$ & $9(39.1)$ & $29(87.9)$ & $14(93.3)$ & $17(85.0)$ & $22.937^{\star \star \star}$ \\
\hline \multicolumn{5}{|l|}{ Technical title ${ }^{c d}$} & -* \\
\hline Junior & $12(52.2)$ & $7(21.2)$ & $2(13.3)$ & $4(20.0)$ & \\
\hline Intermediate & $9(39.1)$ & $19(57.6)$ & $12(80.0)$ & $9(45.0)$ & \\
\hline Senior & $2(8.7)$ & $7(21.2)$ & $1(6.7)$ & $7(35.0)$ & \\
\hline \multicolumn{5}{|l|}{ Educational level c d } & - \\
\hline Junior college & $7(30.4)$ & $5(15.2)$ & $2(13.3)$ & $3(15.0)$ & \\
\hline Bachelor degree & $14(60.9)$ & $24(72.7)$ & $11(73.3)$ & $15(75.0)$ & \\
\hline Master and higher & $2(8.7)$ & $4(12.1)$ & $2(13.3)$ & $2(10.0)$ & \\
\hline Have a child/children ${ }^{c}$ & $9(39.1)$ & $27(81.8)$ & $13(86.7)$ & $15(75.0)$ & $14.944^{* \star}$ \\
\hline $\begin{array}{l}\text { Emergency rescue experience in major public } \\
\text { health events }{ }^{c}\end{array}$ & $3(13.0)$ & $21(63.6)$ & $5(33.3)$ & $4(20.0)$ & $18.408 * * *$ \\
\hline Worked in high epidemic areas of Covid-19 cd & $8(34.8)$ & 23(69.7) & 12(80.0) & 17(85.0) & $14.703^{* *}$ \\
\hline
\end{tabular}


Table 2

Socio-demographic, work experience related characteristics among four PTSD trajectories in non-CC group

\begin{tabular}{|c|c|c|c|c|c|}
\hline \multirow[t]{3}{*}{ Variables } & Resilient & Recovered & Chronic & Delayed & $F$ or $X^{2}$ \\
\hline & $(n=76)$ & $(n=55)$ & $(n=18)$ & $(n=19)$ & \\
\hline & $\begin{array}{l}M(S D) \text { or } n \\
(\%)^{a}\end{array}$ & $\begin{array}{l}M(S D) \text { or } n \\
(\%)^{a}\end{array}$ & $\begin{array}{l}M(S D) \text { or } n \\
(\%)^{a}\end{array}$ & $\begin{array}{l}M(S D) \text { or } n \\
(\%)^{a}\end{array}$ & \\
\hline $\mathrm{Age}^{\mathrm{b}}$ & $33.17(8.43)$ & $33.76(7.30)$ & $34.83(7.29)$ & $33.47(9.20)$ & 0.221 \\
\hline Gender(Female $)^{c d}$ & $69(90.8)$ & $51(92.7)$ & 18(100.0) & $19(100.0)$ & - \\
\hline Profession(Nurses) ${ }^{c d}$ & 67(88.2) & $47(85.5)$ & 17(94.4) & 18(94.7) & 2.113 \\
\hline Years at hospital ${ }^{b}$ & 11.17(9.59) & $11.73(8.29)$ & $13.39(8.94)$ & $12.05(10.53)$ & .0294 \\
\hline marital status ${ }^{c d}$ & $57(75.0)$ & $39(70.9)$ & 14(77.8) & 14(73.7) & - \\
\hline \multicolumn{5}{|l|}{ Technical title $^{c}$} & \multirow[t]{4}{*}{$19.906 * \star$} \\
\hline Junior & $45(59.2)$ & $26(47.3)$ & $7(38.9)$ & $7(36.8)$ & \\
\hline Intermediate & $21(27.6)$ & $25(45.4)$ & $9(50.0)$ & $4(21.1)$ & \\
\hline Senior & 10(13.2) & $4(7.3)$ & $2(11.1)$ & $8(42.1)$ & \\
\hline \multicolumn{5}{|l|}{ Educational level ${ }^{c d}$} & \multirow[t]{4}{*}{-} \\
\hline Junior college & 16(21.1) & 12(21.8) & $2(11.1)$ & $3(15.8)$ & \\
\hline Bachelor degree & $55(72.3)$ & $37(67.3)$ & 15(83.3) & 16(84.2) & \\
\hline Master and higher & $5(6.6)$ & $6(10.9)$ & $1(5.6)$ & $0(0.0)$ & \\
\hline Have a child/children ${ }^{c}$ & $50(65.8)$ & $36(65.5)$ & 15(83.3) & 14(73.7) & 2.565 \\
\hline $\begin{array}{l}\text { Emergency rescue experience in major public } \\
\text { health events }{ }^{c}\end{array}$ & $7(9.2)$ & 17(30.9) & $3(16.7)$ & $3(15.8)$ & $10.334^{*}$ \\
\hline Working in high epidemic areas ${ }^{c d}$ & $1(1.3)$ & $0(0.0)$ & $1(5.6)$ & $0(0.0)$ & - \\
\hline
\end{tabular}

3. Determinants of PTSD trajectories

Table 3, Table 4 reports the factors associated with different trajectory group. In CC group, individuals who has the experience of working in high epidemic areas of Covid-19 significantly differentiated in trajectories of recovery, chronic and delayed from resilient group. The medical staff in the recovery and chronic group were more likely to have emergency rescue experience in major public health events than those in the resilient group. The male medical workers were more tended to be in the delayed group compared to the resilient group. In the non-CC group, those in the delayed group were more likely to be senior medical staff than those in the resilient group. Medical staff who has emergency rescue experience in major public health events were more likely to be in the recovery group, compared to the resilient group. 
Table 3

Predictors of trajectories of Covid-19 related PTSD in CC group

\begin{tabular}{|c|c|c|c|c|c|c|}
\hline \multirow[t]{3}{*}{ Variables } & \multicolumn{2}{|c|}{ Resilient vs Recovery } & \multicolumn{2}{|c|}{ Resilient vs Chronic } & \multicolumn{2}{|c|}{ Resilient vs Delayed } \\
\hline & b (SE) & OR & b (SE) & OR & b (SE) & OR \\
\hline & & $(95 \% \mathrm{Cl})$ & & $(95 \% \mathrm{Cl})$ & & $(95 \% \mathrm{Cl})$ \\
\hline Gender(Female $)^{a}$ & $2.246(1.727)$ & $\begin{array}{l}9.446(0.320- \\
278.556)\end{array}$ & $2.936(1.762)$ & $\begin{array}{l}18.839(0.596- \\
595.343)\end{array}$ & $3.398(1.649)$ & $\begin{array}{l}29.919(1.181- \\
757.943) *\end{array}$ \\
\hline marital status ${ }^{a}$ & $2.315(1.216)$ & $\begin{array}{l}10.121(0.933- \\
109.805)\end{array}$ & $2.794(1.690)$ & $\begin{array}{l}16.339(0.595- \\
448.535)\end{array}$ & $2.456(1.321)$ & $\begin{array}{l}11.663(0.876- \\
155.348)\end{array}$ \\
\hline Technical title $^{b}$ & $-0.377(1.198)$ & $\begin{array}{l}0.686(0.066- \\
7.179)\end{array}$ & $1.131(1.535)$ & $\begin{array}{l}3.099(0.153- \\
62.734)\end{array}$ & $-0.955(1.220)$ & $\begin{array}{l}0.385(0.035- \\
4.207)\end{array}$ \\
\hline Have a child/children ${ }^{a}$ & $1.297(1.213)$ & $\begin{array}{l}3.658(0.039- \\
39.431)\end{array}$ & $1.117(1.489)$ & $\begin{array}{l}3.054(0.165- \\
56.541)\end{array}$ & $0.707(1.324)$ & $\begin{array}{l}2.027(0.151- \\
27.180)\end{array}$ \\
\hline $\begin{array}{l}\text { Emergency rescue } \\
\text { experience in major } \\
\text { public health events }\end{array}$ & $3.503(1.035)$ & $\begin{array}{l}33.217(4.370- \\
252.521) * * \star\end{array}$ & $2.303(1.137)$ & $\begin{array}{l}10.001(1.076- \\
92.955) \text { * }\end{array}$ & $1.585(1.129)$ & $\begin{array}{l}4.877(0.533- \\
44.598)\end{array}$ \\
\hline $\begin{array}{l}\text { Working in high } \\
\text { epidemic areas }\end{array}$ & $2.492(0.878)$ & $\begin{array}{l}12.080(2.160- \\
67.565) * *\end{array}$ & $2.574(0.992)$ & $\begin{array}{l}13.116(1.877- \\
91.625) \text { ** }\end{array}$ & $2.744(0.975)$ & $\begin{array}{l}15.556(2.303- \\
105.082) * *\end{array}$ \\
\hline
\end{tabular}

Table 4

Predictors of trajectories of Covid-19 related PTSD in non-CC group

\begin{tabular}{|c|c|c|c|c|c|c|}
\hline \multirow[t]{2}{*}{ Variables } & \multicolumn{2}{|c|}{ Resilient vs Recovery } & \multicolumn{2}{|c|}{ Resilient vs Chronic } & \multicolumn{2}{|c|}{ Resilient vs Delayed } \\
\hline & b (SE) & OR $(95 \% \mathrm{Cl})$ & b (SE) & OR $(95 \% \mathrm{Cl})$ & b (SE) & OR (95\% Cl) \\
\hline Technical title $^{b}$ & $1.138(0.687)$ & $\begin{array}{l}3.120(0.812- \\
11.983)\end{array}$ & $0.774(0.873)$ & $\begin{array}{l}2.168(0.392- \\
11.992)\end{array}$ & $-1.428(0.724)$ & $\begin{array}{l}0.240(0.058- \\
0.990) *\end{array}$ \\
\hline $\begin{array}{l}\text { Emergency rescue } \\
\text { experience in major public } \\
\text { health events }{ }^{c d}\end{array}$ & $1.438(0.515)$ & $\begin{array}{l}4.211(1.533- \\
11.565) * \star\end{array}$ & $0.455(0.769)$ & $\begin{array}{l}1.576(0.349- \\
7.117)\end{array}$ & $0.296(0.786)$ & $\begin{array}{l}1.344(0.288- \\
6.276)\end{array}$ \\
\hline
\end{tabular}

\section{Risk factors for developing Covid-19-related PTSD}

The analyses comparing the resilient group with non-resilient groups (including all participants with recovery, chronic, and delayed trajectories) are shown in Table 5 and Table 6. In CC group, there were significant differences between resilient and non-resilient groups in the terms of age, gender, marital status, technical title, having a child/children, emergency rescue experience in major public health events, working in high epidemic areas of Covid-19. The independent sample t-test reveals that older medical staff are more likely to have PTSD. The logistic regression model shows that, compared with resilient medical staff, those with PTSD after outbreak of coronavirus were significantly more likely to be married, involved in major public health emergencies and working in high epidemic areas of Covid-19. In non-CC group, there were significant differences between resilient and non-resilient in technical title only, so we stopped the logistic regression analysis. 
Table 5

Resilient and non-resilient medical staff with predictors of Covid-19 related PTSD in CC group

\begin{tabular}{|c|c|c|c|c|c|}
\hline Variables & $\begin{array}{l}\text { Resilient } \\
(n=23) \\
M(S D) \text { or } n \\
(\%)^{a}\end{array}$ & $\begin{array}{l}\begin{array}{l}\text { Non - } \\
\text { resilient }\end{array} \\
(n=68) \\
M(S D) \text { or } n \\
(\%)^{a}\end{array}$ & $t$ or $X^{2}$ & b (SE) & OR (95\% Cl) \\
\hline $\mathrm{Age}^{\mathrm{b}}$ & $31.39(6.37)$ & $35.19(6.50)$ & $-2.437 *$ & $-0.153(0.124)$ & $\begin{array}{l}0.858(0.673- \\
1.094)\end{array}$ \\
\hline Gender(Female $)^{c}$ & 22(95.7) & $52(76.5)$ & $4.163^{*}$ & $-3.410(1.749)$ & $\begin{array}{l}0.033(0.001- \\
1.019)\end{array}$ \\
\hline Profession(Nurses) ${ }^{c}$ & $22(95.7)$ & $58(85.3)$ & 1.735 & & \\
\hline Years at hospital ${ }^{b}$ & $10.39(7.53)$ & 13.21(6.93) & -1.648 & & \\
\hline marital status ${ }^{\complement}$ & $9(39.1)$ & $60(88.2)$ & $22.608 * \star *$ & $-2.890(1.171)$ & $\begin{array}{l}0.056(0.006- \\
0.552)^{\star}\end{array}$ \\
\hline \multicolumn{3}{|l|}{ Technical title ${ }^{c}$} & \multirow[t]{4}{*}{$9.717 * *$} & \multirow[t]{4}{*}{$1.153(0.987)$} & \multirow[t]{4}{*}{$\begin{array}{l}3.168(0.458- \\
21.909)\end{array}$} \\
\hline Junior & 12(52.2) & 13(19.1) & & & \\
\hline Intermediate & $9(39.1)$ & $40(58.8)$ & & & \\
\hline Senior & $2(8.7)$ & $15(22.1)$ & & & \\
\hline \multicolumn{3}{|l|}{ Educational level $^{c}$} & \multirow[t]{4}{*}{2.815} & & \\
\hline Junior college & $7(30.4)$ & $10(14.7)$ & & & \\
\hline Bachelor degree & $14(60.9)$ & $50(73.5)$ & & & \\
\hline Master and higher & $2(8.7)$ & $8(11.8)$ & & & \\
\hline Have a child/children ${ }^{c}$ & $9(39.1)$ & $55(80.9)$ & $14.358 * \star \star$ & $-1.158(1.136)$ & $\begin{array}{l}0.314(0.034- \\
2.908)\end{array}$ \\
\hline $\begin{array}{l}\text { Emergency rescue experience in major public } \\
\text { health events }{ }^{c}\end{array}$ & $3(13.0)$ & $30(44.1)$ & 7.180 ** & $-3.077(1.037)$ & $\begin{array}{l}0.046(0.006- \\
0.352) \\
\star \star\end{array}$ \\
\hline Working in high epidemic areas ${ }^{c}$ & $8(34.8)$ & $52(76.5)$ & $13.298 * \star \star$ & $-2.447(0.804)$ & $\begin{array}{l}0.087(0.018- \\
0.418) \\
\star \star\end{array}$ \\
\hline $\begin{array}{l}\text { Note: Non-resilient group was formed by comb } \\
\text { coronavirus (recovery, chronic, and delayed).a } \\
\text { and percentages were provided for categorical } \\
\text { variable; Chi-square was used. Significant p va a } \\
\text { indicated characteristics. }{ }^{*} p<.05 ;{ }^{* \star} p<.01 ;{ }^{* \star \star}\end{array}$ & $\begin{array}{l}\text { groups of } \mathrm{m} \\
\text { hand standa } \\
\text { ables. b Cont } \\
\text { indicate diffe } \\
.001 .\end{array}$ & $\begin{array}{l}\text { lical staff with } \\
\text { deviation were } \\
\text { lous variable; I } \\
\text { nces in propor }\end{array}$ & $\begin{array}{l}\text { TSD at any } t \\
\text { rovided for } c \\
\text { dependent } t-t \\
\text { on or mean } s\end{array}$ & $\begin{array}{l}\text { me after outbrea } \\
\text { ontinuous variak } \\
\text { st was used. c [ } \\
\text { ores between gi }\end{array}$ & $\begin{array}{l}\text { ef } \\
\text { es. Number } \\
\text { ummy } \\
\text { ups for the }\end{array}$ \\
\hline
\end{tabular}


Resilient and non-resilient medical staff with predictors of Covid-19 related PTSD in non-CC group

\begin{tabular}{|c|c|c|c|}
\hline \multirow[t]{2}{*}{ Variables } & $\begin{array}{l}\text { Resilient } \\
(n=76)\end{array}$ & $\begin{array}{l}\text { Non -resilient } \\
(n=92)\end{array}$ & \multirow[t]{2}{*}{$\operatorname{tor} X^{2}$} \\
\hline & $\mathrm{M}(\mathrm{SD})$ or $\mathrm{n}(\%)^{\mathrm{a}}$ & $M(S D)$ or $n(\%)^{a}$ & \\
\hline $\mathrm{Age}^{\mathrm{b}}$ & $33.17(8.43)$ & $33.91(7.65)$ & -0.435 \\
\hline Gender(Female $)^{c}$ & $69(90.8)$ & $88(95.7)$ & 1.608 \\
\hline Profession(Nurses) ${ }^{c}$ & $67(88.2)$ & $82(89.1)$ & 0.995 \\
\hline Years at hospital ${ }^{\mathrm{b}}$ & $11.17(9.59)$ & $11.91(8.47)$ & -0.517 \\
\hline marital status ${ }^{\mathrm{c}}$ & $57(75.0)$ & $67(72.8)$ & 0.872 \\
\hline \multicolumn{3}{|l|}{ Technical title $^{\mathrm{c}}$} & \multirow[t]{4}{*}{4.375} \\
\hline Junior & $45(59.2)$ & $40(43.5)$ & \\
\hline Intermediate & $21(27.6)$ & $38(41.3)$ & \\
\hline Senior & $10(13.2)$ & $14(15.2)$ & \\
\hline \multicolumn{3}{|l|}{ Educational level ${ }^{\mathrm{C}}$} & \multirow[t]{4}{*}{0.216} \\
\hline Junior college & $16(21.1)$ & $17(18.5)$ & \\
\hline Bachelor degree & $55(72.3)$ & 68(73.9) & \\
\hline Master and higher & $5(6.6)$ & $7(7.6)$ & \\
\hline Have a child/children ${ }^{c}$ & $50(65.8)$ & $65(70.7)$ & 0.456 \\
\hline Emergency rescue experience in major public health events ${ }^{c}$ & $7(9.2)$ & $23(25.0)$ & $7.074^{* *}$ \\
\hline Working in high epidemic areas ${ }^{c d}$ & $1(1.3)$ & $1(1.1)$ & - \\
\hline \multicolumn{4}{|c|}{$\begin{array}{l}\text { Note: Non-resilient group was formed by combining groups of medical staff with PTSD at any time after outbreak of } \\
\text { coronavirus (recovery, chronic, and delayed). a Mean and standard deviation were provided for continuous variables. Number } \\
\text { and percentages were provided for categorical variables. b Continuous variable; Independent t-test was used. c Dummy } \\
\text { variable; Chi-square was used. Significant p values indicate differences in proportion or mean scores between groups for the } \\
\text { indicated characteristics. * } p<.05 ; \star \star \\
\text { were below } 5 \text {. }\end{array}$} \\
\hline
\end{tabular}

5. Differences of trajectories between CC group and non-CC group

In order to study the distribution differences of PTSD score trajectories between CC and non-CC medical workers, we compared the percentages of the same trajectories in CC group and non-CC group. As can be seen from Fig. 3a, the proportion of non-resilient (those with PTSD at any time point) in CC group is more than that of non-CC group. This shows that although COVID-19 has an impact on all staff under the medical system, the CC medical staff is more severe than non-CC medical staff, and their risk of suffering from PTSD is relatively high, the difference was statistically significant $(p=0.002)$ (Table 7$)$. At the same time, the percentage of chronic PTSD and delayed PTSD in CC group was higher than that in non-CC group (Fig. $3 \mathrm{~b}$ ), which indicated that the proportion of PTSD worsening or remaining unchanged in CC group is higher than that in non-CC group. Among them, the occurrence of delayed PTSD was statistically different $(p=0.022)$ (Table 7$)$, while the occurrence of chronic PTSD was not statistically different $(p=0.184)$ (Table 7$)$. It suggests that close contact with the COVID-19 patients not only increased the possibility of PTSD, but also affected the development of PTSD. 
Table 7

Analysis of the difference between the trajectories of CC group and non-CC group

\begin{tabular}{|c|c|c|c|c|c|c|c|c|}
\hline & Resilient & & Recovery & & Chronic & & Delayed & \\
\hline & vs & & vs & & vs & & vs & \\
\hline & Non-Resili & & Non-Recov & & Non-Chron & & Non-Delay & \\
\hline & $\begin{array}{l}\text { Resilient } \\
\mathrm{n}(\%)\end{array}$ & $\begin{array}{l}\text { Non- } \\
\text { Resilient } \\
\mathrm{n}(\%)\end{array}$ & $\begin{array}{l}\text { Recovery } \\
\mathrm{n}(\%)\end{array}$ & $\begin{array}{l}\text { Non- } \\
\text { Recovery } \\
\text { n (\%) }\end{array}$ & $\begin{array}{l}\text { Chronic } \\
\mathrm{n}(\%)\end{array}$ & $\begin{array}{l}\text { Non- } \\
\text { Chronic } \\
\text { n (\%) }\end{array}$ & $\begin{array}{l}\text { Delayed } \\
\mathrm{n}(\%)\end{array}$ & $\begin{array}{l}\text { Non- } \\
\text { Delayed } \\
\text { n (\%) }\end{array}$ \\
\hline $\begin{array}{l}\text { CC } \\
\text { group }\end{array}$ & $23(25.27)$ & $68(74.73)$ & $33(36.26)$ & $58(63.74)$ & $15(16.48)$ & 76(83.52) & $20(21.98)$ & 71(78.02) \\
\hline $\begin{array}{l}\text { Non- } \\
\text { CC } \\
\text { group }\end{array}$ & $76(45.24)$ & $92(54.76)$ & $55(32.74)$ & $113(67.26)$ & $18(10.74)$ & 150(89.29) & 19(11.31) & $149(88.69)$ \\
\hline$x^{2}$ & 9.962 & & 0.327 & & 1.767 & & 5.253 & \\
\hline$p$ & $0.002^{\star *}$ & & 0.567 & & 0.184 & & $0.022 *$ & \\
\hline $\begin{array}{l}\text { Note: N } \\
\text { betwee } \\
\text { Non-Ch } \\
\text { catego }\end{array}$ & $\begin{array}{l}\text { ber and p } \\
\mathrm{C} \text { group a } \\
\text { ic = resili } \\
\text { I variable }\end{array}$ & $\begin{array}{l}\text { entages w } \\
\text { Non-CC gi } \\
\text { recovery } \\
p<.05 ; \star \star\end{array}$ & $\begin{array}{l}\text { vided for } \\
\text { Non-resilie } \\
\text { ed, Non-D } \\
\star \star \star \\
p<.0\end{array}$ & $\begin{array}{l}\text { egorical varia } \\
=\text { recovery }+ \\
\text { yed }=\text { resilien }\end{array}$ & $\begin{array}{l}\text { a Chi-squa } \\
\text { ic + delayec } \\
\text { covery + ch }\end{array}$ & $\begin{array}{l}\text { was used } \mathrm{f} \\
\text { Non-Recove } \\
\text { nic. Then Cl }\end{array}$ & $\begin{array}{l}\text { gorical var } \\
\text { ilient + chr } \\
\text { re was use }\end{array}$ & $\begin{array}{l}\text { or } \\
\text { ic + delayed, }\end{array}$ \\
\hline
\end{tabular}

\section{Discussion}

As the first group of countries affected by the epidemic, China's psychological dynamic process of the epidemic may occur earlier than that of other countries, which can be used as a reference for other countries. This current study conducted a longitudinal investigation to examine the patterns of PTSD in medical workers in the context of COVID-19. Four trajectories of probable PTSD were formed both in $\mathrm{CC}$ group and non-CC group. These results indicate that individual heterogeneity exists in posttraumatic reactions. The results of this study are similar to other research that examine trajectories of PTSD in postpartum women, military members, veterans and earthquake survivors $[13,16,17]$, however, uniquely highlight how the symptoms of PTSD move in tandem through time, helps to expand the knowledge about factors involved in the development of COVID-19 related PTSD and distinguish the different PTSD triggers between close contacts and non-close contacts with Coronavirus.

In CC group, a large number of participants (25.28\%) demonstrated the resilient trajectory, presenting a stable low level of symptoms, scale scores ranging from 36.35 to 33.96 . The recovery trajectory was observed in $36.26 \%$ of the present sample; this trajectory is characterized by an initial increase in symptoms followed by a decrease in symptoms to a low level. The two trajectories means that more than half people can finally show very mild or no symptoms of psychological trauma. Studies suggest that there are two main reasons for this finding. First, few deaths and injuries occurred among medical workers. Second, the state and the public provided excellent support and draw great attention to victims of the disease survivors, which might have had positive psychological impacts on these individuals [2]. Our data shows that medical staff who have emergency rescue experience in major public health events are prone to PTSD, but they also recover quickly. Although the variation tendency of PTSD showed by most of the medical staff in CCs is satisfactory, some are not. We have to pay more attention to the chronic PTSD trajectory (16.48\%) displaying an stable high level of symptoms and the delayed PTSD trajectory (21.98\%) showing delayed symptoms. More than one third of close contacts with COVID-19 have long-term PTSD symptoms. A sustained global epidemic may serving as a continual reminder of the traumatic event, maintaining arousal, and preventing them return to a normal life [9]. The current data demonstrates that the peak scores of the trajectories can reach more than 70 points, which means a severe status. The high rate of chronicity and relatively significant rate highlight the need for continued screening and treatment to promote recovery or prevent the worsening of PTSD symptoms. 
Interestingly, Female gender was found to be an independent protective factor for PTSD in CC group, which inconsistent with a previous study conducted from January 29, 2020, to February 3, 2020 [18]. One possible explanation may be the choice of different timing, because the current study was a longitudinal observation involving two time points. As the mental status of medical staff may gradually change over time, women tend to pay more attention to their experiences and feelings and are more willing to express their emotions. This behavior is conducive to the self-regulation of emotions [19]. It carries important implications in the health care system, where the majority of the nursing staff and health care assistants are female. [9] They are better competent at their jobs on the long run. In addition, unmarried individuals shows good psychological adaptability. A recent case control study on healthcare workers facing the COVID-19 pandemic indicates that married individuals get higher scores in vicarious traumatization symptoms compared to unmarried ones [20]. Besides, it is noteworthy that person who worked in high epidemic areas of Covid-19 likely suffer from PTSD (recovery, chronic, delayed PTSD ). A study [21] investigated a sample of 549 medical staff in Beijing (China), finding 2 to 3 times higher PTSD rates among respondents who worked in high-risk locations and perceived high SARSrelated risks. Reason for this phenomenon may be related to high level of exposure to atmosphere associated with Covid-19 patients. Close contact and direct exposure to the patients' physical and psychological sufferings have made front-line medical workers prone to suffer from higher risk of traumatization or PTSD [20, 22] .

In non-CC group, it was found the rate of PTSD (34.45\%) at 1 month is not as low as we expected and the score (63.63) is very high on the contrary. The incidence and severity were higher than that in previous studies [23, 24].Secondly, non-CCs showed a similar tendency with the CCs that a lot of individuals got chronic or delayed PTSD (22.02\%). One-way ANOVA reveals that it was statistically different not only between groups but also changed over time. Thirdly, it found that the participants in major public health emergencies were closely associated with developing recovery PTSD, consistent with CC group. The possible explanation for the initial rising scores of PTSD is that this kind people were more vigilant to the harmfulness of epidemic and more anxious about virus spread losing control than others. Study suggests that perceived threat can be more strongly associated with the PTSD than object exposure[16]. As a result, they could be more prone to be impacted by the negative emotion in the early days. However, being equipped with specialized knowledge, skills and comprehensive handling abilities of emergency enabling them well adaptive to stress, which made them recover soon. Fourthly, the current study determined the senior medical staff was associated with an elevated risk of developing delayed PTSD. As the epidemic continues for more than 1 year, at the stage of regular epidemic prevention and control, hospitals at all grades dedicate to the prevention and control of the epidemic, as well as work resumption and economic development. Compared to the junior level medical staff, the senior level medical staff is under higher pressure on restoring order of society [25]. In light of the above situation, we should highlight the need for continued screening, timely helping and sufficient social supporting [26, 27], aiming to overcome psychological disorder and promote the PTSD recovery.

Comparative analysis conducted between CCs and non-CCs, and there have something in common: $\mathrm{BB}$ Bth of them have 4 different PTSD symptom trajectories shows extremely similar trend (Fig. 1). खApproximately more than half of the participants(Fig. 3) exposed to the COVID-19 event exhibit acute stress responses immediately and maintain a stable trajectory of euthymia and healthy functioning, which is consistent with the findings of some meta-analyses[28, 29].凶Of the current sample, the proportion with chronic and delayed dysfunction over the follow-up period is not low among CCs and non-CCs.

However, CCs was different in severity and influencing factors from non-CCs. Firstly, CCs take higher risk of PTSD. The PTSD incidence in CCs at 1 month (Recovery + Chronic $=52.74 \%$ ) was higher than non-CCs(43.45\%), and still remain high level at 12 months (Chronic + Delayed $=38.46 \%$ ), which is nearly two times higher than non-CC group $(22.02 \%)$ shows in Fig. 3. Thus, CCs are more likely to suffer from acute PTSD, then may develop chronic or delayed PTSD. Besides, $74.73 \%$ of CCs are non-resilient and $21.98 \%$ of them suffer from delayed PTSD, which is statistically significantly higher than non-CCs. It indicates that close contact with the COVID-19 patients not only increased the possibility of PTSD, but also affected the development of PTSD. Secondly, with the resilient group serving as the reference, bivariate logistic regression shows that the predictive factors have great differences between CCs and non-CCs. Several predictors were found in CC group, while limited found in non-CC group which was not affected by socio-demographic factors. With regard to consistent risk factors, the recovery, chronic and delayed group have been merged to expand the sample size. Then the multivariate logistic regressions find an consistent result with previous analysis of bivariate. The phenomenon of different influencing factors between CCs and non-CCs means that the methods of psychological intervention may need to be differentiated although these two groups share the same symptoms and shows similar trajectory changes. In addition, whether the main predictors of medical staff who non-close contact with COVID-19 patients were other more complex factors remains an important direction for further research. 
The study has certain limitations. Firstly, online self-administer and non-rigorous random sampling could have affected the representativeness and reliability of the results. And a certain amount of cases were lost during the second follow-up due to the long observation period. In the current situation, the most important task is to contain the epidemic, and it is very important to reduce people gathering, which cause a major obstacle to this study to carry out large-scale face-to-face investigations. Secondly, more complex factors should be taken into account in the future study, such as personality characteristics or coping skills, etc. The relevant factors which may affect the trajectories of non-CC group from our analysis is limited.

\section{Conclusions}

Results from this study indicate that there are four different forms of COVID-19 related PTSD courses of medical staff. Although many of them seem to have no PTSD or rapidly recover, a considerable number of them have acute PTSD and long-term PTSD, both in CCs and non-CCs. The results support the negative impact of the COVID-19 pandemic on the mental health of all medical staff, especially CCs. The medical system deserves more public attention and social support to identify and treat its psychiatric issues. Meanwhile, the identified factors from this study may contribute to identify medical workers with PTSD symptoms so that preventive and treatment interventions can offer to targeted people. According to our results, interventions should focus particularly on CCs of male gender, married, working in high epidemic areas of COVID-19.

\section{Abbreviations}

ANOVA

Analysis of variance; CC group:close contact group; non-CC group:non-close contact group; Cl:Confidence Interval; OR:Odds ratios; PHEIC:Public Health Emergency of International Concern; PTSD:Post-traumatic stress disorder; PTSD-SS:Posttraumatic Stress Disorder Self-Rating Scale; SARS:severe acute respiratory syndrome; WHO:World Health Organization.

\section{Declarations}

\section{Acknowledgements}

The authors would like to thank Dr. Shen for his advice on this study with study design and statistical analysis. Last but not least, credit should also go to all the participants who engaged in this study and unconditionally shared their experiences after the outbreak of COVID-19.

\section{Authors' contributions}

All authors have read and approved the manuscript. Han Sheng: Writing - original draft and writing of manuscript. Rong Wang: Writing - original draft, performed data analysis and obtained funding. Ming Yao: Study concept and design. Qinghe Zhou: Provided consultation on analyses and reviewed the manuscript. Zhihong Zhu: Assisted in writing of manuscript. Yeping Fei: Writing \& editing, assisted in writing of manuscript. Xuyan Zhou: Assisted in writing of manuscript. Qifei Liu: Data collection. Conflicts of interest

The authors have no conflicts of interest to declare.

\section{Funding}

This work was supported by the programs of anti-epidemic special project of universities of directly affiliated hospitals in 2020 (Y202043807) by Zhejiang Provincial Department of Education, the Key Discipline Established with Zhejiang Province, Jiaxing City Jointly (2019-ss-ttyx), Key Discipline of Anesthesiology of Jiaxing City (2019-zc-06) and Key Discipline of Clinical Nursing Innovation of Jiaxing City(2019-CX-02).

\section{Ethics approval and consent to participate}

Ethical approval was obtained from The Institutional Review Board of the First Hospital of Jiaxing (LS2020-305). All methods were performed in accordance with the Declaration of Helsinki and the relevant guidelines and regulations. All participants read an online information sheet and gave informed consent to participate before responding to the questionnaires. 


\section{Consent for publication}

N/A

\section{Competing interests}

The authors declare that they have no competing interests.

\section{Author details}

${ }^{1}$ Department of Nursing, Affiliated Hospital of Jiaxing University, Jiaxing, Zhejiang, China. ${ }^{2}$ Department of Anesthesiology and Pain Medicine, The Affliated Hospital of Jiaxing University, Zhejiang Province, Jiaxing, China. ${ }^{3}$ Department of Oncology, Wuhan Fourth Hospital, Wuhan, Hubei, China.

\section{References}

1. Carmassi C, Foghi C, Dell'Oste V, Cordone A, Bertelloni CA, Bui E, Dell'Osso L. PTSD symptoms in healthcare workers facing the three coronavirus outbreaks: What can we expect after the COVID-19 pandemic. Psychiatry research. 2020;292:113312.

2. Fan F, Long K, Zhou Y, Zheng Y, Liu X. Longitudinal trajectories of post-traumatic stress disorder symptoms among adolescents after the Wenchuan earthquake in China. Psychological medicine. 2015;45(13):2885-96.

3. Nishiura H, Jung SM, Linton NM, Kinoshita R, Yang Y, Hayashi K, Kobayashi T, Yuan B, Akhmetzhanov AR. The Extent of Transmission of Novel Coronavirus in Wuhan, China, 2020. Journal of clinical medicine 2020, 9(2).

4. Wang C, Pan R, Wan X, Tan Y, Xu L, Ho CS, Ho RC. Immediate Psychological Responses and Associated Factors during the Initial Stage of the 2019 Coronavirus Disease (COVID-19) Epidemic among the General Population in China. Int J Environ Res Public Health. 2020;17(5):1729.

5. Peeri NC, Shrestha N, Rahman MS, Zaki R, Tan Z, Bibi S, Baghbanzadeh M, Aghamohammadi N, Zhang W, Haque U. The SARS, MERS and novel coronavirus (COVID-19) epidemics, the newest and biggest global health threats: what lessons have we learned? Int J Epidemiol. 2020;49(3):717-26.

6. Killgore WDS, Taylor EC, Cloonan SA, Dailey NS. Psychological resilience during the COVID-19 lockdown. Psychiatry research. 2020;291:113216.

7. Dutheil F, Mondillon L, Navel V. PTSD as the second tsunami of the SARS-Cov-2 pandemic. Psychological medicine 2020:1-2.

8. Chen Q, Liang M, Li Y, Guo J, Fei D, Wang L, He L, Sheng C, Cai Y, Li X, et al. Mental health care for medical staff in China during the COVID-19 outbreak. The lancet Psychiatry. 2020;7(4):e15-6.

9. Mak IW, Chu CM, Pan PC, Yiu MG, Ho SC, Chan VL. Risk factors for chronic post-traumatic stress disorder (PTSD) in SARS survivors. Gen Hosp Psychiatry. 2010;32(6):590-8.

10. WHO Coronavirus. 2021. (COVID-19) Dashboard, 27 July 2021. https://covid19.who.int/.

11. Jerome L, Feduccia AA, Wang JB, Hamilton S, Yazar-Klosinski B, Emerson A, Mithoefer MC, Doblin R. Long-term follow-up outcomes of MDMA-assisted psychotherapy for treatment of PTSD: a longitudinal pooled analysis of six phase 2 trials. Psychopharmacology. 2020;237(8):2485-97.

12. Brier ZMF, Connor J, Legrand AC, Price M. Different trajectories of PTSD symptoms during the acute post-trauma period. J Psychiatr Res. 2020;131:127-31.

13. Armenta RF, Walter KH, Geronimo-Hara TR, Porter B, Stander VA, LeardMann CA. Longitudinal trajectories of comorbid PTSD and depression symptoms among U.S. service members and veterans. BMC Psychiatry. 2019;19(1):396.

14. Gorsuch RL. The general factor in the test anxiety questionnaire. Psychological reports. 1966;19(1):308.

15. Lei M, Li C, Xiao X, Qiu J, Dai Y, Zhang Q. Evaluation of the psychometric properties of the Chinese version of the Resilience Scale in Wenchuan earthquake survivors. Compr Psychiatr. 2012;53(5):616-22.

16. Cheng J, Liang YM, Zhou YY, Eli B, Liu ZK. Trajectories of PTSD symptoms among children who survived the Lushan earthquake: A four-year longitudinal study. J Affect Disord. 2019;252:421-7. 
17. Dikmen-Yildiz P, Ayers S, Phillips L. Longitudinal trajectories of post-traumatic stress disorder (PTSD) after birth and associated risk factors. J Affect Disord. 2018;229:377-85.

18. Lai J, Ma S, Wang Y, Cai Z, Hu J, Wei N, Wu J, Du H, Chen T, Li R, et al. Factors Associated With Mental Health Outcomes Among Health Care Workers Exposed to Coronavirus Disease 2019. JAMA network open. 2020;3(3):e203976.

19. Song X, Fu W, Liu X, Luo Z, Wang R, Zhou N, Yan S, Lv C. Mental health status of medical staff in emergency departments during the Coronavirus disease 2019 epidemic in China. Brain Behav Immun. 2020;88:60-5.

20. Li Z, Ge J, Yang M, Feng J, Qiao M, Jiang R, Bi J, Zhan G, Xu X, Wang L, et al. Vicarious traumatization in the general public, members, and non-members of medical teams aiding in COVID-19 control. Brain Behav Immun. 2020;88:916-9.

21. Wu P, Fang Y, Guan Z, Fan B, Kong J, Yao Z, Liu X, Fuller CJ, Susser E, Lu J, et al. The psychological impact of the SARS epidemic on hospital employees in China: exposure, risk perception, and altruistic acceptance of risk. Canadian journal of psychiatry Revue canadienne de psychiatrie. 2009;54(5):302-11.

22. Maunder RG, Lancee WJ, Rourke S, Hunter JJ, Goldbloom D, Balderson K, Petryshen P, Steinberg R, Wasylenki D, Koh D, et al. Factors associated with the psychological impact of severe acute respiratory syndrome on nurses and other hospital workers in Toronto. Psychosom Med. 2004;66(6):938-42.

23. Pietrzak RH, Van Ness PH, Fried TR, Galea S, Norris FH. Trajectories of posttraumatic stress symptomatology in older persons affected by a large-magnitude disaster. J Psychiatr Res. 2013;47(4):520-6.

24. Pietrzak RH, Feder A, Singh R, Schechter CB, Bromet EJ, Katz CL, Reissman DB, Ozbay F, Sharma V, Crane M, et al. Trajectories of PTSD risk and resilience in World Trade Center responders: an 8-year prospective cohort study. Psychological medicine. 2014;44(1):205-19.

25. Kang P, Lv Y, Hao L, Tang B, Liu Z, Liu X, Liu Y, Zhang L. Psychological consequences and quality of life among medical rescuers who responded to the 2010 Yushu earthquake: A neglected problem. Psychiatry research. 2015;230(2):517-23.

26. Ahmad S, Feder A, Lee EJ, Wang Y, Southwick SM, Schlackman E, Buchholz K, Alonso A, Charney DS. Earthquake impact in a remote South Asian population: psychosocial factors and posttraumatic symptoms. Journal of traumatic stress.

2010;23(3):408-12.

27. Feder A, Ahmad S, Lee EJ, Morgan JE, Singh R, Smith BW, Southwick SM, Charney DS. Coping and PTSD symptoms in Pakistani earthquake survivors: purpose in life, religious coping and social support. J Affect Disord. 2013;147(1-3):156-63.

28. Bonanno GA, Brewin CR, Kaniasty K, Greca AM: Weighing the Costs of Disaster. Consequences, Risks, and Resilience in Individuals, Families, and Communities. Psychological science in the public interest: a journal of the American Psychological Society 2010, 11(1):1-49.

29. Foa EB, Stein DJ, McFarlane AC. Symptomatology and psychopathology of mental health problems after disaster. J Clin Psychiatry. 2006;67(Suppl 2):15-25.

\section{Figures}




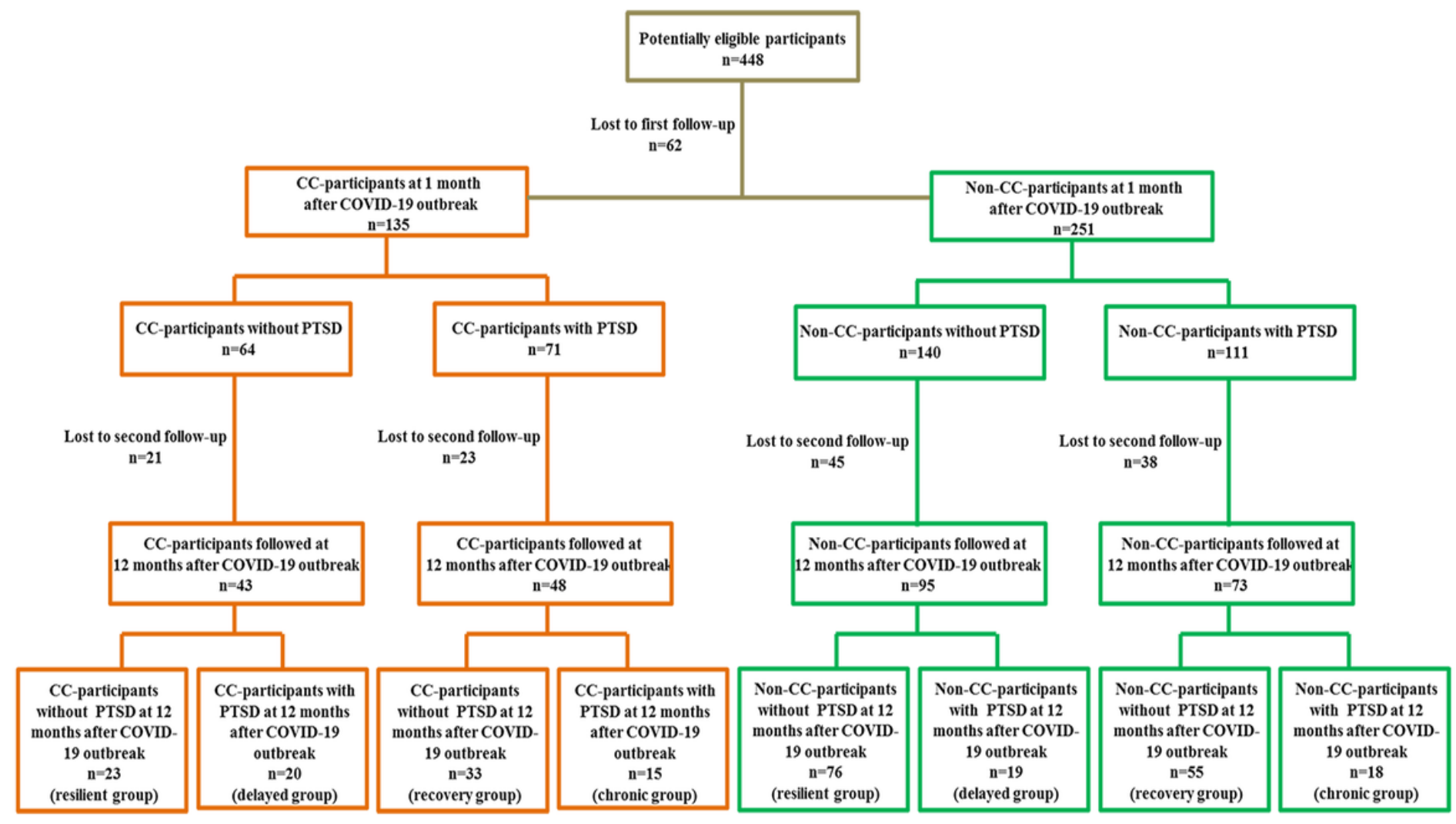

\section{Figure 1}

Study flow diagram 


\section{CC group $(\mathrm{N}=91)$}

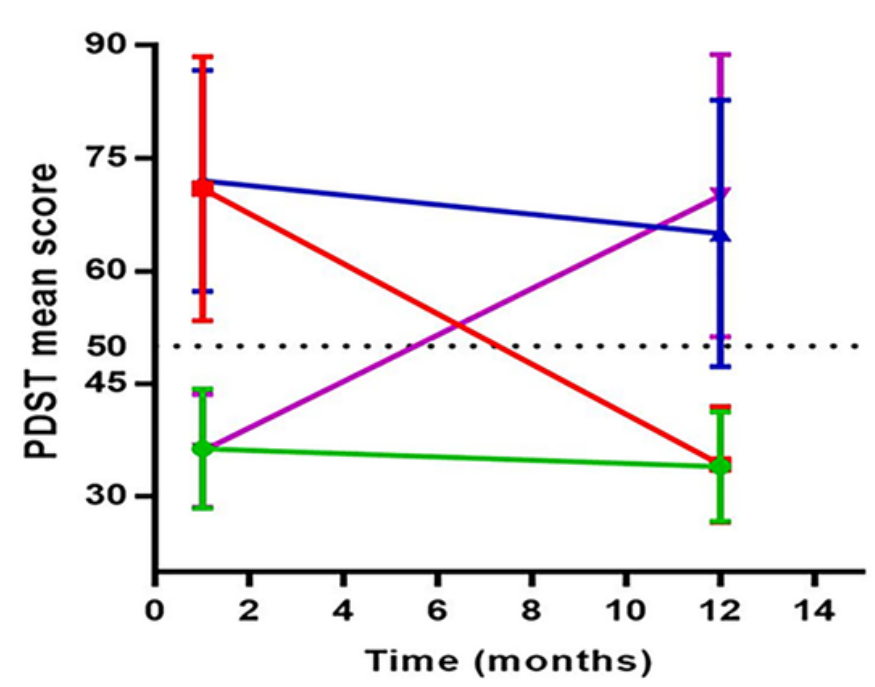

$\multimap$ Resilient(scores from $\mathbf{3 6 . 3 5}$ to $\mathbf{3 3 . 9 6 )}$

$\rightarrow$ Recovery (scores from 70.97 to 34.27 )

- Chronic(scores from 72.00 to 65.00 )

$\rightarrow$ Delayed(scores from 36.05 to 70.00 )
non-CC group( $\mathrm{N}=168)$

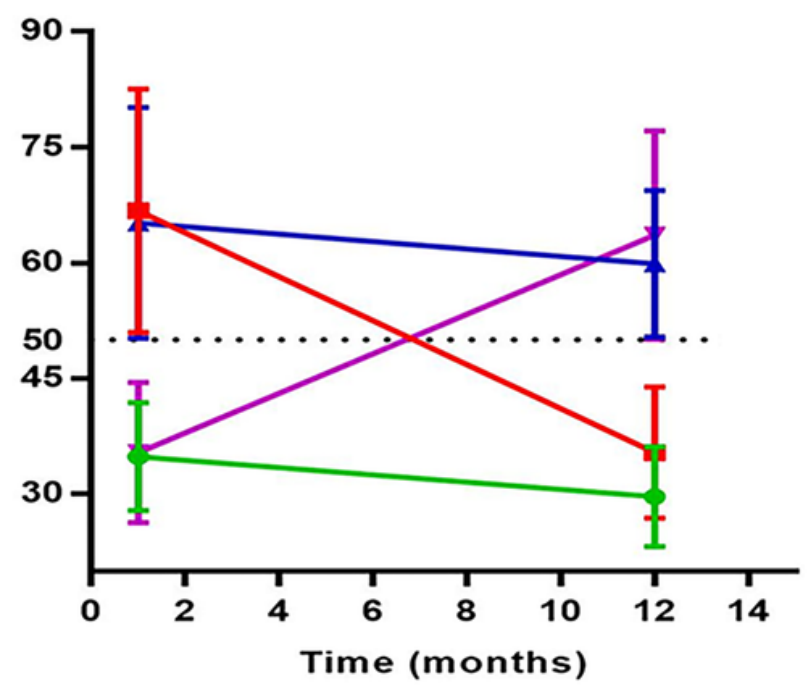

$\multimap$ Resilient(scores from 34.83 to 29.66)

$\rightarrow$ Recovery (scores from 66.75 to 35.40 )

$\rightarrow$ Chronic(scores from 65.17 to 59.89 )

$\rightarrow$ Delayed(scores from 35.37 to 63.63 )

Figure 2

COVID 19-related PTSD score trajectories of CC group and non-CC group at 1 month and 12 months after outbreak of coronavirus.
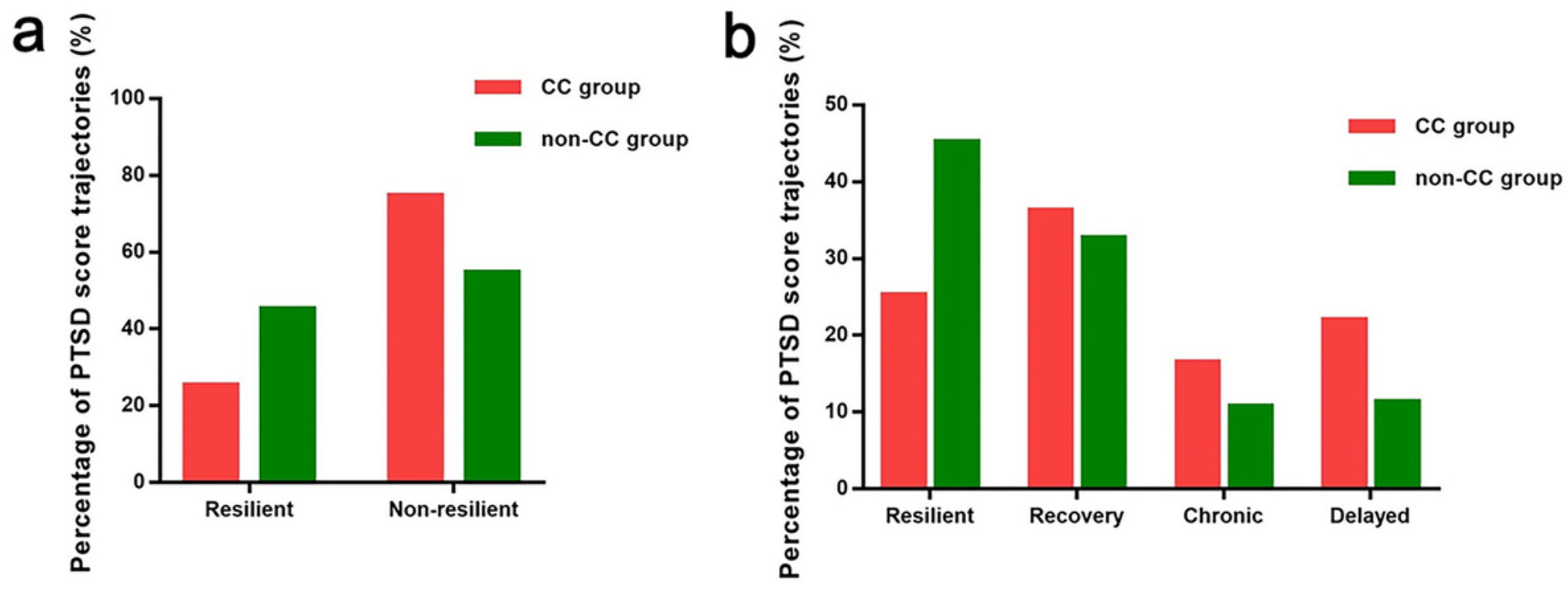

Figure 3

Differences of trajectories between CC group and non-CC group 